


About IJMA
International Journal of Medical Arts is the Official Scientific Journal
of the Damietta Faculty of Medicine, Al-Azhar University, Egypt
It is an International, Open Access, Double-blind, Peer-reviewed,
monthly-published (starting January 2022) Journal
The First Issue was published in July 2019
Published under the following license: Creative Commons
Attribution-ShareAlike 4.0 International Public License (CC BY-SA
4.0).
The Egyptian Knowledge Bank hosts the web site and supports
IJMA follows the regulations of the International Committee of
Medical Journal Editors
IJMA is a member of the International Society of Managing and
Technical Editors
IJMA is indexed in the "Directory of Open Access Journals"
[Indexed on 15 January 2021], Index Copernicus and J-Gate [29-6-
IJM21].
IJMA Listed in
"Publons", "Academic resource index [ResearchBib]", "Electronics journal
Jibrary", "Eurasian Scientific Journal Index", World Catalogue of Scientific
WorldCat and "Citefactor"




\begin{tabular}{c|c|c|} 
Available online at Journal Website \\
https://ijma.journals.ekb.eg/ \\
Main Subject [Basic Sciences] \\
Specific subject [Public Health]
\end{tabular}

Original Article

\title{
Medical Students' Performance and Perception with Flipped versus Traditional Classroom Models
}

\author{
Randa M. Said ${ }^{[1]}$, Marwa B. AwadAllah ${ }^{[2]}$, Ghada M. Salem ${ }^{* 2]}$ \\ ${ }^{1}$ Department of Family Medicine, Faculty of Medicine, Zagazig University, Egypt \\ ${ }^{2}$ Department of Public Health and Community Medicine, Faculty of Medicine, Zagazig University, Egypt
}

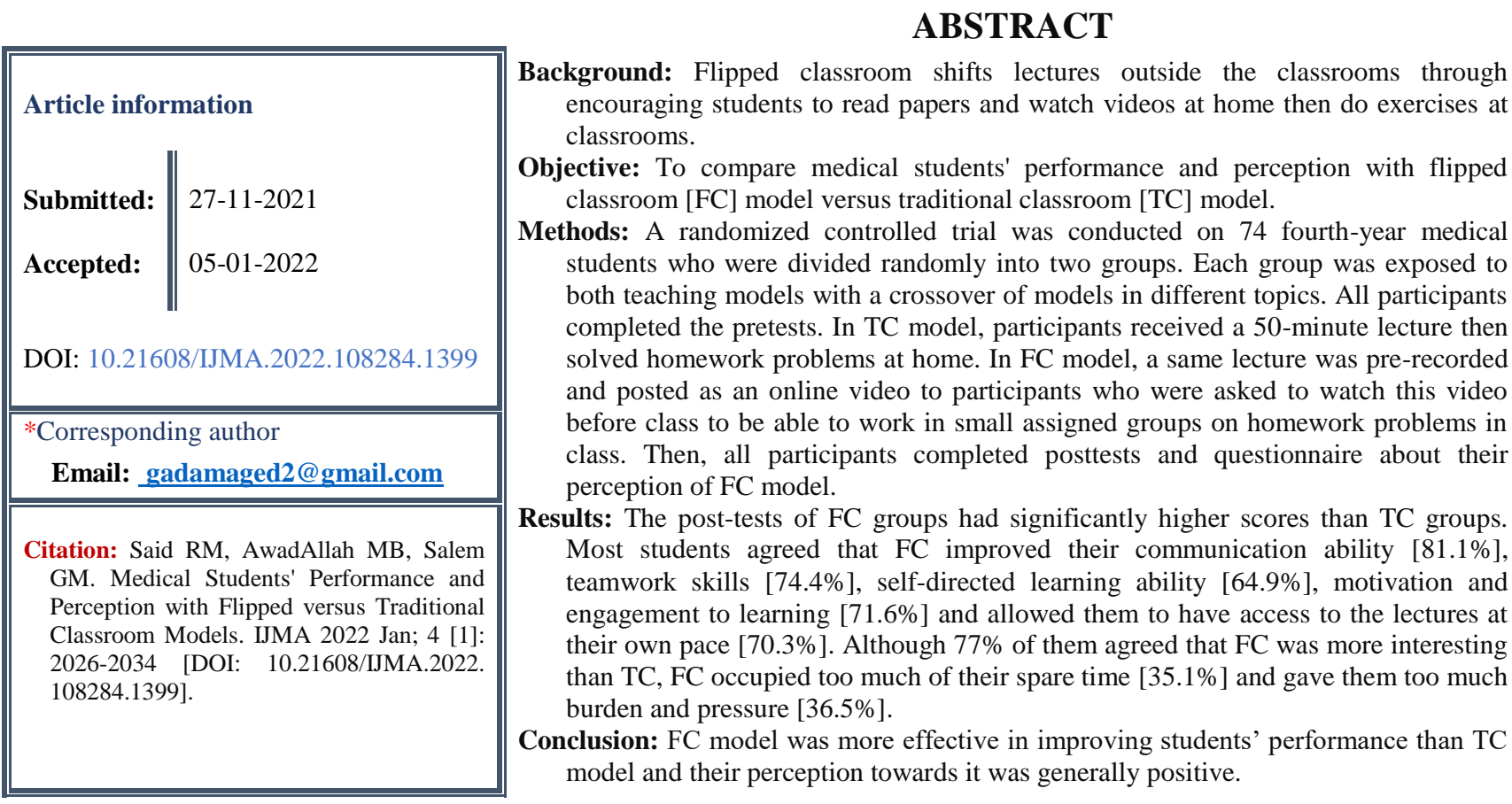

Keywords: Medical student; Flipped classroom; Traditional classroom; Performance; Perception.

This is an open-access article registered under the Creative Commons, ShareAlike 4.0 International license [CC BY-SA 4.0] [https://creativecommons.org/licenses/by-sa/4.0/legalcode.

\section{INTRODUCTION}

Universities are responsible for generating innovative graduates who are able to respond to complex socio-ecological problems ${ }^{[1]}$. Recently, there is a growing interest about the general quality of medical education which has created a necessity for reform of existing teaching methods in order to better prepare students for prospective careers in medical practice $^{[2]}$. Medical courses are usually taught through traditional teaching strategies, such as tutorials, didactic lectures and practical classes that mainly depend on the passive transfer of knowledge from the lecturer to the learner ${ }^{[3]}$. This causes students to lose motivation and lack the self-study capacity ${ }^{[4]}$. Learning should be an active process rather than a passive one where the role of the instructors is to mentor and facilitate the learning process. Instructors are constantly challenged to look for novel ways to engage learners in the class to make the education process more effective ${ }^{[5]}$. 
The flipped classroom is one of the novel active learning strategies which reverse the traditional learning process. In the traditional classroom, students attend regular lectures in classrooms, and then do exercise at home while flipped classroom shifts lectures outside the classrooms through encouraging students to read papers and watch videos at home then do exercises at classrooms ${ }^{[6]}$.

Flipped teaching has two essential components: the out-of-class and the in-class learning activity ${ }^{[7]}$. In the out-of-class learning, the students are provided by background knowledge as homework before the class session. The in-class learning is considered as the crucial component of flipped teaching where face-to-face lectures, are opportunities to deepen, broaden and apply the students understanding of the out-of-class material thought 'active learning activities' in class time [8]. These learning activities help students to practice concepts and interact with peers within the classroom so they build team work skills, mutual understanding and confidence ${ }^{[6]}$.

Although flipped classrooms usage has become more and more common in medical education, the results about its effectiveness were contradictory and its effectiveness compared to conventional learning methods hasn't been proved so far. According to systemic review conducted by Chen et al., there was variety in measures of effectiveness of FC; consequently, it is vital to assess the impact of the flipped classroom every time that it is introduced to a new setting. Although the FC is a promising teaching strategy to rise learners' motivation and engagement, more solid evidence on its influence on changes in knowledge and skills are necessary ${ }^{[9]}$.

Flipped classroom was recently introduced as new learning/teaching method in the new Integrated Competency Based $\mathrm{MBBCH}$ program at Faculty of Medicine, Zagazig University in the academic year 2018/2019 and at the time of our study, it was applied only on $1^{\text {st }}$ and $2^{\text {nd }}$ year medical students without evaluation of its effect on the performance and perception of these students compared to the conventional educational methods. So, we decided to assess this effect by conducting this study on the students belonged to the traditional $\mathrm{MBBCH}$ program who never exposed before to flipped classroom teaching.

\section{THE AIM OF THE WORK}

Our study aimed at improving the quality of the medical education by using new method of teaching. Our research question was "in medical students how did the Flipped Classroom method of teaching affect their performance and perception compared to traditional method?"

The objective of our study was to compare medical students' performance and perception with the Flipped Classroom [FC] model versus the Traditional Classroom [TC] model.

\section{METHODS}

\section{Study design}

A randomized controlled trial was conducted in Community Medicine Department of Faculty of Medicine at Zagazig University, Sharkia Governorates, Egypt during the academic year 2019/2020 from the beginning to the end of January 2020.

\section{Study participants}

Sample size was calculated to be 68 students using Open Epi I program depending on the following parameters; confidence interval 95\%, power of test $80 \%$, ratio between two groups $1: 1$, and the percent of students with improved performance with FC model was $89.6 \%$ versus $56.8 \%$ with TC model according to previous study ${ }^{[10]}$. Taking into consideration $20 \%$ dropouts, the total sample size was 82 participants.

Our study participants were chosen from the 4th year medical students because; firstly, they belonged to the traditional $\mathrm{MBBCH}$ program so they never exposed before to FC model. Secondly, they were the most accessible to us as the community medicine curriculum from which we derived the topics used in the intervention is taught in the 4th year of traditional $\mathrm{MBBCH}$ program. 
Students were chosen as follow; the faculty of Medicine divided the 4th year medical students into four groups; one group out of these four groups was selected randomly as a cluster sample. By using simple random sample technique, the sample size was selected form the chosen group.

The selected participants were allocated randomly and equally into two groups by computer to ensure blinding and concealed allocation; each group consisted of 42 students. By using cross over design method, the two groups were exposed to both teaching [FC and TC] models to avoid the bias of individual variations between students that could affect the results i.e., as our intervention depended on teaching of two topics, during teaching of the first topic, one of the study groups exposed to FC model and the other group exposed to TC model while during teaching of the second topic, we reversed the models where the group which exposed to FC model in the first topic was exposed to TC model in the second topic and vice versa. At the end of the intervention, each group consisted of 37 students with total of 74 students in both groups as eight students were excluded.

\section{Exclusion criteria}

At the start of intervention, we excluded students who refused to participate and replaced them by other students who accepted to participate to keep the calculated sample size taking into consideration the possible dropouts throughout the study while during the intervention, we excluded students who lost because of their absence from some sessions, incomplete tests or technical errors prevented them from watching the online videos before attending FC sessions.

\section{Data collection tools}

1. Pretests and Posttests: they were used to measure the student's performance. They were formulated to cover the learning outcomes of two topics of the same weight and level of difficulty from 4th year medical Curriculum in the area of Communicable Diseases [Tuberculosis and Hepatitis].
Each test consisted of 10 multiple choice questions ranging in complexity as established by Bloom's taxonomy from low to high cognitive skill. Low level questions evaluated basic comprehension and definitions. Medium level questions challenged students to apply learned concepts. High level questions allowed students to use more than learned concept to analyze data and draw conclusions ${ }^{[11]}$.

At the end of the trial, the same 10 questions were used for posttest. Each correct answer was given one point with total score of 10 points. Researchers shared their test questions with experts in the fields of Community Medicine for review and testing for content validity. The responses of the experts were scored from 4-1 points; $4=$ =strongly relevant, $3=$ relevant, $2=$ little relevant, and $1=$ not relevant. The test validity was calculated in view of experts' conclusion and found to be [93\%]. Reliability test was also done whereas Cronbach's Alpha equals 0.87.

2. Questionnaire about Student's Perception of FC Model: It was used to measure the students' perception of the FC model. It was a structured, self-administered 15-question questionnaire. It composed of 4 sections; the students' overall satisfaction about FC [3 items], their self-perceived competencies after FC [5 items], their opinions about positive aspects of $\mathrm{FC}$ [4 items], and negative aspects of FC [3 items]. The students were asked to rate their responses on three points Likert scale [agree, neutral, disagree]. Reliability test was also done whereas Cronbach's Alpha equals 0.74.

\section{Experimental tools}

The out-of-class activities of FC model included creating online videos of the selected topics using PowerPoint presentation program. Videos were peer-reviewed and modified according to feedback. They ranged from 2530 minutes in length. They were uploaded through Learning Management System [LMS] for each study group. The in-class activities of FC model included preparing quizzes and assignments. 


\section{Study procedure}

The authors were the teachers for both groups in both teaching models [TC and FC]. The study took two weeks; the 1st week for studying tuberculosis topic and the 2nd one for studying hepatitis topic. Each week started with asking all participants to answer the pretests uploaded to them through the LMS. In TC model, students received a 50-minute lecture that used a mix of PowerPoint presentation and white board work with open discussion and answering questions then homework problems were allocated to be answered at home. In FC model, a same lecture was pre-recorded, and posted to students as an online video, then students were asked to watch this video before class and come to class ready to work in small assigned groups on homework problems. Identical homework problems were allocated to both classes. Textbook readings prior to class were also allocated to both classes. At the end of each week, all participants were asked to complete posttests and questionnaire about their perception of FC model uploaded to them through LMS. The flow of the study was presented in Figure [1].

\section{Statistical management}

The collected data was analyzed by using SPSS [Statistical Package for the Social Sciences] version 20.0. Prior to statistical analysis, all data were tested for normality and homogeneity using the Kolmogorov-Smirnov and Bartlett's tests. The appropriate statistical tests were used as follow; if data were normally distributed, paired t test to compare pretests and posttests of same group and student's t test to compare either pretests or posttests of two groups in each topic were used and in case of skewed data, Mann-Whitney test was used instead of student's t test.

\section{Ethical considerations}

The research protocol was approved by Ethics Committee of Faculty of Medicine, Zagazig University, Egypt [zu-IRb\#6041]. An official permission was also obtained from the head of Community Medicine Department, Faculty of Medicine, Zagazig University. An informed verbal consent was obtained from all participants after simple and clear explanation of the research objectives. Participants were informed about their right to reject participation and to withdraw whenever they need without giving reasons and with no consequences. Total confidentiality of any given information was assured.

\section{RESULTS}

Table [1] shows the basic characteristics of the study groups. The two groups were comparable where there were no statistically significant differences between two groups regarding gender, age and mean of total final performance scores of $1^{\text {st }}, 2^{\text {nd }}$ and $3^{\text {rd }}$ years of Faculty of Medicine.

Table [2] shows students' performance with the FC model versus TC model. In both studied topics, there were no differences between students of the FC groups and TC groups in pretest scores, indicating that the baseline knowledge of these groups was comparable. The students of the FC groups had significantly higher post-tests scores than those of the TC groups $[9.3 \pm 1.06$ vs. $4.4 \pm 2.6, \quad \mathrm{P}=0.00$ in hepatitis topic and $9.1 \pm 0.77$ vs. $4.1 \pm 3.2, \mathrm{P}=$ 0.00 in tuberculosis topic]. Furthermore, the students of the FC groups had significantly higher post-tests scores in all types of questions [low level, medium level and high-level] than those of the TC groups. Regarding the comparison between pretest and posttest results, the students of the FC groups had significantly higher scores in all posttests compared to pretests $[9.3 \pm 1.06$ vs. $2.1 \pm 2.3, \mathrm{P}=$ 0.00 in hepatitis topic and $9.1 \pm 0.77$ vs. $4.1 \pm 1.3$, $\mathrm{P}=0.00$ in tuberculosis topic] while the students of the TC groups had significantly higher scores in hepatitis posttest compared to hepatitis pretest $[4.4 \pm 2.6$ vs. $2.7 \pm 3.2, \mathrm{P}=0.00]$ and non-significantly different scores in tuberculosis posttest compared to tuberculosis pretest $[4.1 \pm 3.2$ vs. $4.3 \pm 1.3, \mathrm{P}=0.9]$.

Table [3] shows student's perception towards the FC model where $77 \%$ of the students agreed that $\mathrm{FC}$ was more interesting than TC. Most of them also agreed that FC improved their communication ability [81.1\%], teamwork skills [74.4\%] and their self-directed learning ability [64.9\%]. FC helped $71.6 \%$ of 
them to be motivated and engaged to learning and allowed $70.3 \%$ of them to have access to the lectures at their own pace. Videos were better for learning than text-based content from the perspective of $67.6 \%$ of students. Around half of the students reported neutral responses regarding; FC allowed teachers for more individual interaction with students [50\%], FC occupied too much of their spare time [55.4\%], FC gave them too much burden and pressure [55.4\%], and a traditional teacher lead lesson was better than a lesson video [50\%].

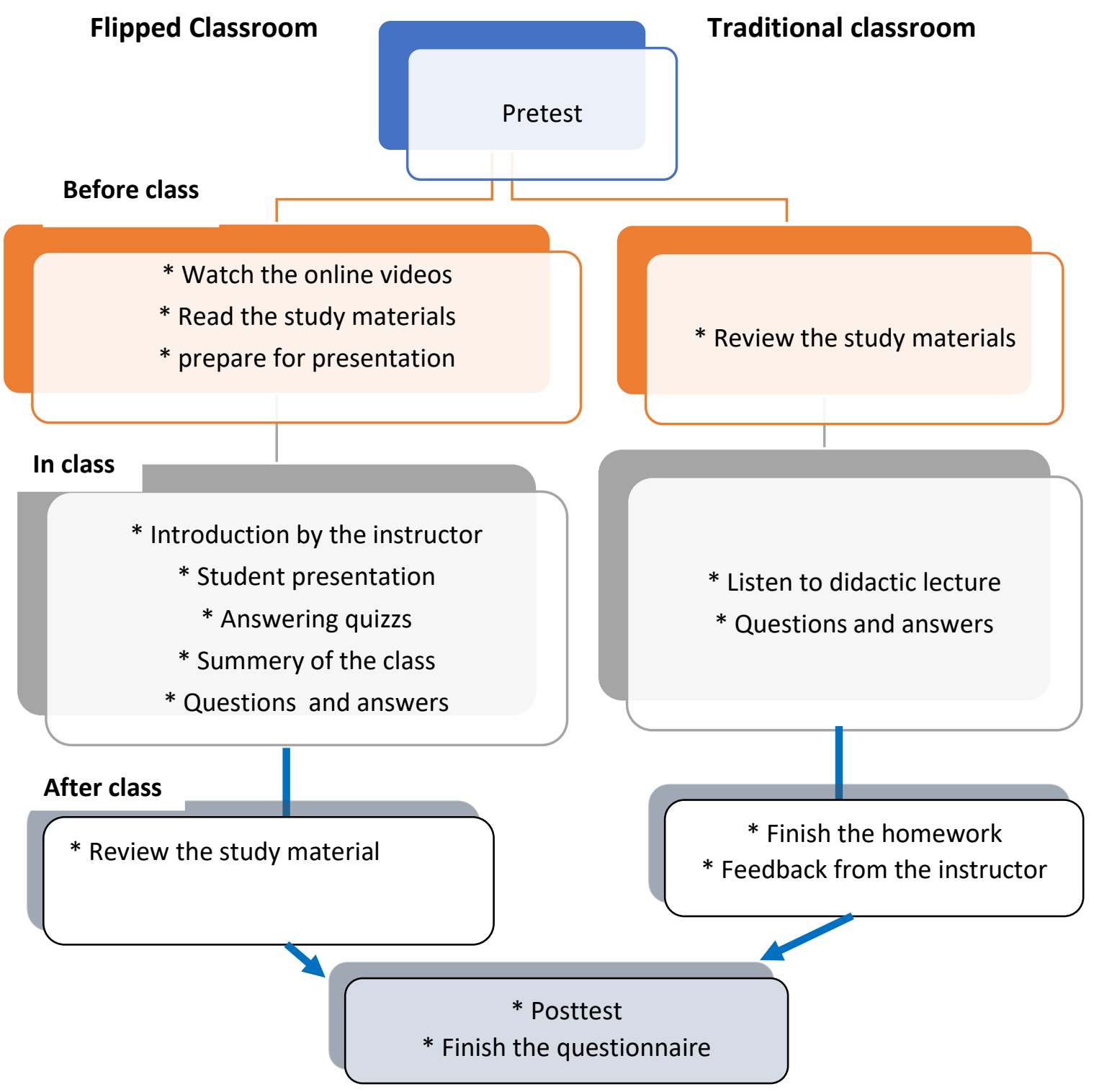

Figure [1]: Flow diagram showing the flipped and traditional classroom models

Table [1]: Basic characteristics of the study groups

\begin{tabular}{|l|l|c|c|c|c|}
\multicolumn{2}{|c|}{ Characteristics } & $\mathbf{1}^{\text {st }}$ group [No.37] & $2^{\text {nd }}$ group [No.=37] & Test & p value \\
\hline Gender & Males No [\%] & $15[40.5]$ & $19[51.4]$ & $\mathrm{X}^{2}=0.87$ & 0.35 \\
& Females No [\%] & $22[59.5]$ & $18[48.6]$ & & \\
\hline Age [Mean \pm SD] & $21 \pm 76$ & $21 \pm 71$ & $\mathrm{t}=0.00$ & 1.00 \\
\hline Performance* $[$ Mean \pm SD] & $2138 \pm 48$ & $2159 \pm 89$ & $\mathrm{t}=1.26$ & 0.21 \\
\hline
\end{tabular}

Performance $*=$ Final total performance scores of 1 st, 2 nd and 3rd years of Faculty of Medicine 
Table [2]: Students' performance with the Flipped Classroom [FC] versus Traditional Classroom [TC]

\begin{tabular}{|c|c|c|c|c|c|c|}
\hline & \multicolumn{3}{|c|}{ Hepatitis topic } & \multicolumn{3}{|c|}{ Tuberculosis topic } \\
\hline & $\begin{array}{c}\text { FC } \\
\text { Mean } \pm \text { SD }\end{array}$ & $\begin{array}{c}\text { TC } \\
\text { Mean } \pm \text { SD }\end{array}$ & $\begin{array}{c}\text { Statistical } \\
\text { test } \\
\text { [P value]! }\end{array}$ & $\begin{array}{c}\text { FC } \\
\text { Mean } \pm \text { SD }\end{array}$ & $\begin{array}{c}\text { TC } \\
\text { Mean } \pm \text { SD }\end{array}$ & $\begin{array}{c}\text { Statistical } \\
\text { test }[\mathbf{P} \\
\text { value]! }\end{array}$ \\
\hline $\begin{array}{l}\text { Pretest } \\
\text { Low Level Q } \\
\text { Medium Level Q } \\
\text { High Level Q } \\
\text { Total } \\
\end{array}$ & $\begin{array}{c}0.8 \pm 0.8 \\
0.5 \pm 1.0 \\
0.78 \pm 1.2 \\
2.1 \pm 2.3\end{array}$ & $\begin{array}{l}1.2 \pm 1.1 \\
0.4 \pm 0.7 \\
1.1 \pm 1.5 \\
2.7 \pm 3.2\end{array}$ & $\begin{array}{l}{[0.43]^{* *}} \\
{[0.79]^{* *}} \\
{[0.26]^{* *}} \\
{[0.96]^{* *}}\end{array}$ & $\begin{array}{c}0.64 \pm 0.78 \\
0.43 \pm 0.6 \\
2.7 \pm 1.0 \\
4.1 \pm 1.3\end{array}$ & $\begin{array}{c}0.64 \pm 0.82 \\
0.67 \pm 0.47 \\
3.1 \pm 1.1 \\
4.3 \pm 1.3\end{array}$ & $\begin{array}{c}{[0.93]^{* *}} \\
{[0.02]^{* *}} \\
1.4[0.15]^{*} \\
0.88[0.3]^{*}\end{array}$ \\
\hline $\begin{array}{l}\text { Posttest } \\
\text { Low Level Q } \\
\text { Medium Level Q } \\
\text { High Level Q } \\
\text { Total }\end{array}$ & $\begin{array}{l}2.7 \pm 0.41 \\
2.9 \pm 0.22 \\
3.6 \pm 0.75 \\
9.3 \pm 1.06\end{array}$ & $\begin{array}{c}1.8 \pm 0.8 \\
1.05 \pm 0.9 \\
1.4 \pm 1.6 \\
4.4 \pm 2.6\end{array}$ & $\begin{array}{c}5.9[0.00]^{*} \\
11.2[0.00]^{*} \\
7.3[0.00]^{*} \\
10.6[0.00]^{*}\end{array}$ & $\begin{array}{c}2.5 \pm 0.5 \\
2.9 \pm 0.22 \\
3.6 \pm 0.75 \\
9.1 \pm 0.77\end{array}$ & $\begin{array}{l}1.5 \pm 0.9 \\
1.5 \pm 0.9 \\
1.4 \pm 1.6 \\
4.1 \pm 3.2\end{array}$ & $\begin{array}{c}4.5[0.0]^{*} \\
11.2[0.0]^{*} \\
7.3[0.0]^{*} \\
9.2[0.0]^{*}\end{array}$ \\
\hline $\begin{array}{l}\text { Paired-t test }[P \\
\text { value]! }\end{array}$ & {$[0.00]$} & {$[0.00]$} & & {$[0.00]$} & [0.9] & \\
\hline
\end{tabular}

* Student $\mathrm{t}$ test; ** Mann -Whitney test; ! Significant difference $\mathrm{p}<0.05$

Table [3]: Student's Perception of the Flipped Classroom [FC] Model

\begin{tabular}{|c|c|c|c|}
\hline \multirow[t]{2}{*}{ Item } & \multicolumn{3}{|c|}{ Total $=74$ students } \\
\hline & $\begin{array}{c}\text { Agree } \\
\text { No. [\%] }\end{array}$ & $\begin{array}{c}\text { Neutral } \\
\mathbf{N}[\%]\end{array}$ & $\begin{array}{c}\text { Disagree } \\
\mathbf{N}[\%]\end{array}$ \\
\hline \multicolumn{4}{|l|}{ The overall satisfaction about FC: } \\
\hline 1- FC was more interesting than TC. & $57[77.0]$ & $12[16.2]$ & $5[6.8]$ \\
\hline 2- I prefer FC over TC in my upcoming classes. & $41[55.4]$ & $22[29.7]$ & $11[14.9]$ \\
\hline 3- I'd like to suggest FC to other students. & $39[52.7]$ & $23[31.1]$ & $12[16.2]$ \\
\hline \multicolumn{4}{|l|}{ The student's self-perceived competencies after FC: } \\
\hline 4-FC improved my self-directed learning ability. & 48 [64.9] & $14[18.9]$ & $12[16.2]$ \\
\hline 5- FC improved my communication ability. & $60[81.1]$ & $9[12.2]$ & $5[6.7]$ \\
\hline 6- FC improved my critical thinking ability. & $43[58.1]$ & $18[24.3]$ & $13[17.6]$ \\
\hline 7- FC improved my ability to give presentations. & $43[58.1]$ & $23[31.1]$ & $8[10.8]$ \\
\hline 8-FC improved my teamwork skills & $55[74.4]$ & 14 [18.9] & $5[6.7]$ \\
\hline \multicolumn{4}{|l|}{ The positive aspects of $\mathrm{FC}$ : } \\
\hline 9- FC increases motivation and engagement to learning. & $53[71.6]$ & $16[21.6]$ & $5[6.8]$ \\
\hline 10- FC allows me to have access to the lectures at my own pace. & $52[70.3]$ & $20[27.0]$ & $2[2.7]$ \\
\hline 11- FC allows teachers for more individual interaction with students. & $27[36.5]$ & $37[50.0]$ & $10[13.5]$ \\
\hline 12- Videos are better for learning than text-based content & $50[67.6]$ & $22[29.7]$ & $2[2.7]$ \\
\hline \multicolumn{4}{|l|}{ The negative aspects of $\mathrm{FC}$ : } \\
\hline 13- A traditional teacher lead lesson is better than a video lesson. & $30[40.5]$ & $37[50.0]$ & $7[9.5]$ \\
\hline 14- FC occupies too much of my spare time. & $26[35.1]$ & $41[55.4]$ & $7[9.5]$ \\
\hline 15- FC gives me too much burden and pressure & $27[36.5]$ & $41[55.4]$ & $6[8.1]$ \\
\hline
\end{tabular}

\section{DISCUSSION}

Our study has shown that the FC model improved students' performance compared to the TC model, as the mean scores of all posttests advanced substantially in the FC model. This can be explained by studying the posted materials in advance of the class in the FC model helped learners to acquire the fundamental concepts efficiently, which supplied the facilitator additional space during the class time to focus on the lecture crucial aspects, practice, and ability to solve problems.
This explanation is supported by Milman ${ }^{[12]}$ who reported that the FC model provides additional time in class for more interactive teaching, student participation, and focused discussion.

Literature review revealed that the results about FC effectiveness were contradictory. Our results are consistent with the majority of revised studies which concluded that the FC model improved or at least didn't harm students' performance compared to the TC model. Examples of these studies include Veeramani et al. ${ }^{[13]}$ who reported that the 
performance of first year medical students in the neuro-anatomy after the FC sessions was better than those who had only traditional teaching. Also, Bhagat et al. ${ }^{[14]}$ found that high school students attending flipped classroom achieved a higher degree of accomplishment in learning mathematics concepts relative to student undergoing traditional teaching methods. Tanget al. ${ }^{[2]}$ found that fourth year medical students in the FC performed better on the posttest of ophthalmology when compared to those from the TC. Cabi ${ }^{[15]}$ indicated that the use of the FC model didn't have significant impact on the students' academic achievement compared to TC, and Aggarwal et al. ${ }^{[16]}$ who found that the mean assessment scores of first year medical students in biochemistry in the flipped and traditional classrooms were statistically insignificant and concluded that learning gain not affected by the method of teaching. Few studies only e.g., Gundlach et al. [17] concluded that students in TC preformed significantly better than the students in FC.

Furthermore, our post-tests of the FC groups had significantly higher scores compared to the TC groups in all types of questions including; low level questions assessing knowledge, medium level questions assessing application and high-level questions assessing analysis. This can be explained by FC allows more retention of knowledge through enabling the student to revisit the recorded lecture more than one time even immediately before exam. Also, FC builds the student's application and analysis through in-class group discussion and teachers' individual support. Group discussion or cooperative learning has often been referred to as a means of promoting higher order thinking skills and has been proved to positively correlate to the students' academic achievement ${ }^{[18]}$. These results are different from Morton and Colbert-Getz ${ }^{[18]}$ and Van Vliet et al. ${ }^{[20]}$ who reported that FC students performed better than TC students only on high cognitive level question assessing analysis but there were no differences in performance between them for low cognitive level questions assessing knowledge or application.

Regarding students' perception of FC model, although $77 \%$ of participants were satisfied with the new learning model, around $50 \%$ of them only would prefer FC in their upcoming classes and would suggest FC to other students. This can be attributed to the negative aspects of FC model reported in this study. The first negative aspect was, some students preferred a traditional teacher lead lesson over a lesson video. This can be explained by although good instructors will do their best to build-in effective communication activities while students watch the video, they may still unable to provide enough communication activities for all types of learners. Also, students are unable to ask questions and get immediate targeted answer to difficult concept if they watch the video alone and they had to wait for class time to ask instructor or peers which delay comprehension ${ }^{[12]}$. The other negative aspects of FC model were time consuming and stressful pre-class preparation efforts which were mentioned in other studies ${ }^{[2,21]}$.

Regarding the student's self-perceived competencies after FC, most students agreed that FC model helped them to improve their communication ability, teamwork skills and self-directed learning ability and some of them agreed that FC model helped them to improve their critical thinking ability and ability to give presentations. These competencies are considered indirect learning outcomes to FC model and are causes for positive student perceptions toward it as reported in many previous studies ${ }^{[2,13,21,22]}$.

Regarding other positive aspects of FC model, most students agreed that FC model increased their motivation and engagement to learning. This is consistent with Nouri ${ }^{[23]}$ who noted that the majority of students had a positive attitude towards the FC model which was strongly correlated with their perception of increased engagement, motivation, and successful learning. Another positive aspect of FC model was accessibility of online recorded lectures to students at their own pace leading to better motivation in terms of self-directed preview learning ${ }^{[24,25]}$. Also most of students agreed that videos were better for learning than text-based content and this is consistent with 
many other studies provided that good instructional and technical quality of the video is achieved ${ }^{[12,24,25]}$.

This study provides further evidence on the effectiveness of the flipped classroom over the traditional classroom as an important strength of this study was the attempt of the researchers as much as possible to limit confounders through exposing the same participants to the two models of learning by the same instructors in topics of same weight and level of difficulty.

Limitations of the study: First, dependence on self-assessment of the participants to indirect learning outcomes such as communication skills, critical thinking skills although it was better to consider objective assessment methods. Second, we investigated only the pre-class time and not investigated the after-class time that students took. Students in the TC may spend more time after class to review the lecture and do the homework assignments while students in FC may spend more time before the class to watch the online video and prepare themselves to work during class time. Third, performance assessment was limited to two topics and it may be more meaningful when applied for multiple and diverse topics however, broad implementation of FC in the curriculum would require training of more faculty members in such approach. Also, the entire public health course cannot be taught using flipped classroom. Hence, it is important to plan before delivering a course using a flipped classroom model. Finally, a long-term learning gain was not assessed in the current study.

\section{Conclusion}

The flipped classroom model was effective in improving students' performance compared to traditional classroom model and their perception towards it was generally positive as it improved their soft skills and increased their motivation and engagement to learning. So, we recommend that the flipped classroom model should be incorporated in teaching of the different medical curricula as it can play a successful role in preparation of future physicians with better professional performance. Finally, this study can be a guide for instructors on how to alter the learning environment from traditional classroom to flipped classroom.

Funding: This research did not receive any specific grant from any funding agency in the public, commercial or not-for-profit sector.

Conflict of interest: The authors declare that they have no conflict of interest.

\section{REFERENCES}

1. Cortese AD. The critical role of higher education in creating a sustainable future. Plann High Educ. 2003 Mar 15;31[3]:15-22.

2. Tang F, Chen C, Zhu Y, Zuo C, Zhong Y, Wang $\mathrm{N}$, et al. Comparison between flipped classroom and lecture-based classroom in ophthalmology clerkship. Med Educ Online. 2017;22[1]:1395679. DOI: 10.1080/10872981. 2017.1395679.

3. Zahid MA, Varghese R, Mohammed AM, Ayed AK. Comparison of the problem based learning-driven with the traditional didacticlecture-based curricula. Int J Med Educ. 2016 Jun 12;7:181-7. DOI: 10.5116/ijme.5749.80f5.

4. Dickinson BL, Lackey W, Sheakley M, Miller L, Jevert S, Shattuck B. Involving a real patient in the design and implementation of casebased learning to engage learners. Adv Physiol Educ. 2018 Mar 1;42[1]:118-122. DOI: 10.1152/advan.00174.2017.

5. Strayer JF. How learning in an inverted classroom influences cooperation, innovation and task orientation. Learn Environ Res. 2012 Jul;15[2]:171-193. DOI: 10.1007/s10984-0129108-4

6. Bishop JL, Verleger MA. The Flipped Classroom: A Survey of the Research. In: Proceedings of the Annual Conference of the American Society for Engineering Education, 2013. p. 6219.

7. O'Flaherty J, Phillips C. The use of flipped classrooms in higher education: A scoping review. Internet High Educ. 2015 Apr 1;25:8595. DOI: 10.1016/j.iheduc.2015.02.002.

8. Cheng YH, Weng CW. Factors influence the digital media teaching of primary school teachers in a flipped class: A Taiwan case study. South Afric J Educ. 2017 Mar;37[1]:112. DOI: $10.15700 /$ saje.v37n1a1293.

9. Chen F, Lui AM, Martinelli SM. A systematic 
review of the effectiveness of flipped classrooms in medical education. Med Educ. 2017 Jun;51[6]:585-597. DOI: 10.1111/medu. 13272.

10. Unal Z, Unal A. Comparison of student performance, student perception, and teacher satisfaction with traditional versus flipped classroom models. Int J Inst. 2017;10[4]:14564. DOI: 10.12973/iji.2017.1049a.

11. Bloom B, Engelhart M, Furst E, Hill W, Krathwohl D. Taxonomy of education objectives: the classification of educational goals. New York: David McKay Company, Inc.; 1956.

12. Milman NB. The flipped classroom strategy: What is it and how can it be used? Distance Learning. 2012;9[3]:85-87.

13. Veeramani R, Madhugiri VS, Chand P. Perception of MBBS students to "flipped class room" approach in neuroanatomy module. Anat Cell Biol. 2015 Jun;48[2]:138-43. DOI: 10.5115/acb.2015.48.2.138.

14. Bhagat KK, Chang CN, Chang CY. The impact of the flipped classroom on mathematics concept learning in high school. J Educ Techn Soci. 2016 Jul 1;19[3]:134-42.

15. Cab1 E. The impact of the flipped classroom model on students' academic achievement. Int Rev Res Open Distributed Learn. 2018;19[3]:202-221. DOI:10.19173/irrodl. v19i3.3482

16. Aggarwal K, Thakur B, Agrawal M, Jhajharia S, Madaan H, Mahapatra SK. A comparative study between flipped classroom and traditional lecture-based classroom in first year medical students. Int J Res Med Sci. 2019;7 [10]:3654-3659. DOI: 10.18203/23206012. ijrms20194191.

17. Gundlach E, Richards KA, Nelson D, Levesque-Bristol C. A comparison of student attitudes, statistical reasoning, performance, and perceptions for web-augmented traditional, fully online, and flipped sections of a statistical literacy class. J Stat Educ. 2015 Mar 1;23[1]. DOI: 10.1080/10691898.2015. 11889723.
18. Hoorani BH. Impact of cooperative learning in developing students' cognitive abilities for academic achievement. J Educ Educat Dev. 2014;1[2]:145-155.

19. Morton DA, Colbert-Getz JM. Measuring the impact of the flipped anatomy classroom: The importance of categorizing an assessment by Bloom's taxonomy. Anat Sci Educ. 2017 Mar;10[2]:170-175. DOI: 10.1002/ase.1635.

20. van Vliet EA, Winnips JC, Brouwer N. FlippedClass Pedagogy Enhances Student Metacognition and Collaborative-Learning Strategies in Higher Education But Effect Does Not Persist. CBE Life Sci Educ. 2015 Fall;14[3]:ar26. DOI: 10.1187/cbe.14-090141 .

21. Lo CK, Hew KF. A critical review of flipped classroom challenges in K-12 education: possible solutions and recommendations for future research. Res Pract Technol Enhanc Learn. 2017;12[1]:4. DOI: 10.1186/s41039016-0044-2.

22. Farrah M, Qawasmeh A. English Student's Attitudes Towards Using Flipped Classrooms in Language Learning at Hebron University. Res Eng Lang Pedagog. 2018; 6[2]:275-294.

23. Nouri J. The flipped classroom: for active, effective and increased learning-especially for low achievers. Int J Educ Techn Higher Educ. 2016 Dec;13[1]:33. DOI: 10.1186/s41239016-0032-z.

24. Clark KR. The effects of the flipped model of instruction on student engagement and performance in the secondary mathematics classroom. J Educator Online. 2015 Jan;12[1]: 91-115.

25. Wang YH. Could a mobile-assisted learning system support flipped classrooms for classical Chinese learning?. J Comput Assist Learn. 2016 Sep;32[5]:391-415. 


\section{$1=\sqrt{202(2)}$}

international Journal https://ijma.journals.ekb.eg/ Print ISSN: 2636-4174 Online ISSN: 2682-3780

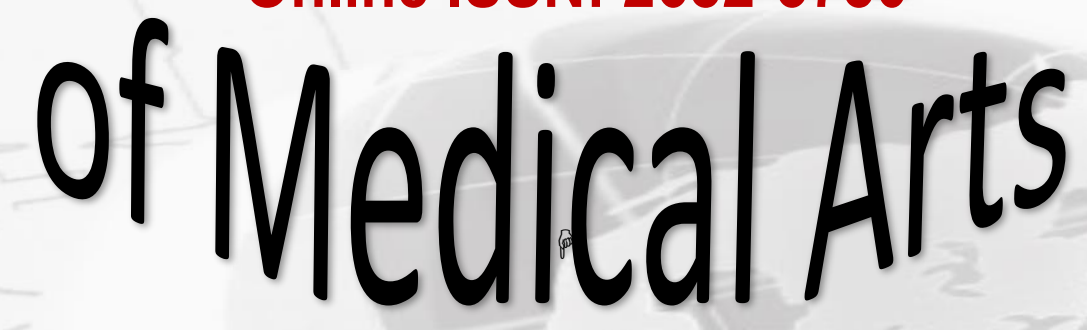

